EGU21-8086, updated on 16 Nov 2021

https://doi.org/10.5194/egusphere-egu21-8086

EGU General Assembly 2021

(c) Author(s) 2021. This work is distributed under

the Creative Commons Attribution 4.0 License.

\title{
The utilization of biochar as a conditioner for soil enrichment
}

Sarka Sovova, Natalie Storkova, Marie Kurkova, Vojtech Enev, and Michal Kalina

Brno University of Technology, Faculty of Chemistry, Brno, Czechia (xcsovova@vutbr.cz)

The soil is becoming less fertile mainly due to today's way of land cultivation, erosion, lack of organic matter, aridity etc. Since soil represents the crucial environment for the life of a broad variety of living organisms, it is also a key material in agricultural production, one of the most important sources of food production, therefore, it is important to start working on its refining or at least on sustaining its crucial properties. There are few possible solutions to improve fertility, water retention, enhance plant growth etc. involving soil conditioners such as lignite, lignohumate or biochar. Biochar is a carbon-rich solid product of thermochemical conversion of biomass under anaerobic conditions (pyrolysis) abounding with attractive chemical (greenhouse gasses reduction, nutrient leaching reduction, plant growth enhancement) and physical (e.g. particles size distribution, porosity and surface area) properties.

In present work, we focused on the study of the effect the application of EBC (European Biochar Certificate) certified biochar on growth of a model plant (Zea mays) in different - common widespread soil types in the Czech republic (Regosol, Chernozem, Cambisol, Fluvisol...). Corn seeds were germinated in moist paper wipe for three days and planted into the flowerpot. The used dosage of biochar was 0,10 and $20 \mathrm{~g}$ per $1 \mathrm{~kg}$ of dry weight of individual soils. Corn plants were cultivated under controlled conditions (temperature, moisture, cyclic irrigation, controlled light exposure etc.). Corn growth - height and number of leaves were measured three times a week for three months. The individual used soils samples and biochars were characterized before and after experiments by routine physico-chemical methods $(\mathrm{pH}$, content of organic matter and humic substance, humic acids/fulvic acids ratio, total extractable macro and microelements...). 